\title{
Learning and knowing as semiosis: Extending the conceptual apparatus of semiotics
}

\section{Cary Campbell ${ }^{1}$, Alin Olteanu ${ }^{2}$, Kalevi Kull ${ }^{3}$}

\begin{abstract}
If all knowing comes from semiosis, more concepts should be added to the semiotic toolbox. However, semiotic concepts must be defined via other semiotic concepts. We observe an opportunity to advance the state-of-the-art in semiotics by defining concepts of cognitive processes and phenomena via semiotic terms. In particular, we focus on concepts of relevance for theory of knowledge, such as learning, knowing, affordance, scaffolding, resources, competence, memory, and a few others. For these, we provide preliminary definitions from a semiotic perspective, which also explicates their interrelatedness. Redefining these terms this way helps to avoid both physicalism and psychologism, showcasing the epistemological dimensions of environmental situatedness through the semiotic understanding of organisms' fittedness with their environments. Following our review and presentation of each concept, we briefly discuss the significance of our embedded redefinitions in contributing to a semiotic theory of knowing that has relevance to both the humanities and the life sciences, while not forgetting their relevance to education and psychology, but also social semiotic and multimodality studies.
\end{abstract}

Keywords: affordance; competence; scaffolding; semiotic learning; semiotic resource; theory of knowledge; memory; umwelt

The theoretical strength and useful applicability of semiotics is largely dependent on the adequacy and richness of its conceptual apparatus. The greater part of the semiotic toolbox comes from a few classic authors, with considerable enrichment and diversification occurring between the 1960s and 1980s. The decades after that

\footnotetext{
1 Faculty of Education, Simon Fraser University, Vancouver, Canada; e-mail: cary_campbell@ sfu.ca.

2 Department of Semiotics, University of Tartu, Jakobi St. 2, Tartu 51005, Estonia; Kaunas University of Technology, Kaunas, Lithuania; e-mail: alin.olteanu@ut.ee.

3 Department of Semiotics, University of Tartu, Jakobi St. 2, Tartu 51005, Estonia; e-mail: kalevi.kull@ut.ee.
} 
have not added many new concepts. Mostly, this recent period is characterized by its focus on discussions about the areas of applicability of existing concepts and about the relationships (complementarity, or incompatibility, or fittedness, or synthesis, etc.) between the conceptual systems of different semiotic schools.

Some conceptual (and terminological) changes are seemingly irreversible: for instance, the earlier opposition between signs and symbols in some approaches has led to the acceptance of symbols as subtypes of signs; after the initial opposition between Saussurean and Peircean semiotics, attempts have been made to accommodate both, making a natural space for Saussurean semiotics in a wider theory, at the same time avoiding the pansemiotic approach (e.g. Stables 2012; Favareau, Kull 2015); interpretation and meaning-making are understood as universal features of semiosis; semiosis is identified as taking place in a wide range of living systems. The latter aspect has opened the area for the development of biosemiotics (together with the important border area of cognitive semiotics), which became in this way a field of discussions on general semiotics.

Our thesis is that semiosis as the fundamental process of meaning-making implies, as its central aspects, learning, memory, and knowing; and that semiosic activity assumes and is framed by resources, competence, affordances, and scaffolding. All these listed concepts describe components or aspects of semiosis; therefore, they can be incorporated within contemporary semiotics. For this, however, these concepts should be understood through intra-semiotic lenses. We understand a concept to belong to the semiotic toolbox (i.e., to be a semiotic concept) if it is defined via other concepts of semiotics. Thus, our task is to redefine these mentioned concepts accordingly, within a semiotic framework.

The authors of this article met for some seminars in Tartu in the spring of 2019, and divided the work in the following way: Cary Campbell led the study on affordances and scaffolding, Alin Olteanu on resources and competence, Kalevi Kull added the introduction, and we together connected it into a study on the semiotics of learning and knowing.

\section{Learning, knowing, and other aspects of cognition - extending the list of basic semiotic concepts}

While, according to an old formula, life and cognition are coextensive (e.g., Heschl 1990), it is also rather natural to accept that cognition and semiosis are coextensive. ${ }^{4}$ Therefore, it is necessary to explicate the relationships of all the

$4 \quad$ See also Zlatev 2003. 
above-mentioned cognitive concepts to the concept of semiosis. Semiotic definitions for the concepts of cognitive processes are necessary for a comprehensive general semiotic theory. The recent attention that semiotic research is paying to aspects of cognition (Eco 1999; Zlatev, Sonesson, Konderak 2016; Konderak 2018; Mittelberg 2019; Brandt 2020) demonstrates this need. ${ }^{5}$

To establish the whole network of cognitive semiotic concepts is beyond our current task. Our aim here is (1) to argue for the importance of importing a row of concepts into the basic semiotic theory, and (2) to sketch some of these relationships.

A look into semiotic dictionaries clearly suggests the necessity of such an integrating effort. As shown in Table 1, the terms describing learning and cognition are mostly absent in the classic semiotic terminology.

Thus, in this paper, we sketch the relations between some elements of the general semiotic account of learning. Within our model, these elements include the embedded and interrelated concepts of resource, competence, affordance, and scaffolding. We explore these notions as connected to the seemingly more primary biosemiotic concepts of umwelt and learning.

We consider that the future development of semiotic theory will rely on these terms - often plagued with hidden homunculi and psychologism - redefined in general semiotic terms; i.e. without reducing them to mentalistic schemas or production rules, but rather, as sign-relations, descriptions of the ways in which organisms live, interact and co-evolve with their environment.

Each of these concepts (take, as a clear example, 'learning') is used in inconsistent variations through different discourses. Therefore, as part of our methodology, we will present each concept individually, carefully tracing (a) the term's common meaning and introduction; (b) its historical development and use in different disciplines, including semiotics; and (c) redefinition of the term within a general semiotic theory of knowledge. Following our presentation of each concept, we briefly discuss the significance of our embedded redefinitions, in contributing to a semiotic theory of knowing that has relevance to both the humanities and the life sciences, while not forgetting their relevance to education and psychology, but also social semiotic and multimodality studies.

5 The biosemiotic glossary project has partly a similar aim, to enrich the conceptual system of general semiotics (see Favareau, Gare 2017; Rodríguez Higuera, Kull 2017; Tønnessen 2015; Tønnessen, Magnus, Brentari 2015). Also, see the volume Concepts for Semiotics (Rodríguez Higuera, Bennett 2016). 
Table 1. Inclusion of some cognitive semiotic terms in some dictionaries of semiotics (- no such entry; + corresponding entry exists).

\begin{tabular}{l|l|l|l|l|l}
\hline \multicolumn{1}{c|}{ Dictionary } & $\begin{array}{l}\text { Colapietro } \\
\text { Entries }\end{array}$ & Bouissac 1998 & $\begin{array}{l}\text { Martin, } \\
\text { Ringham } \\
2006\end{array}$ & $\begin{array}{l}\text { Sebeok, } \\
\text { Danesi 2010 }\end{array}$ & $\begin{array}{l}\text { Cobley } \\
2010\end{array}$ \\
\hline affordance & - & + & - & - & - \\
\hline competence & + & - & + & $\begin{array}{l}\text { competence/ } \\
\text { performance }\end{array}$ & + \\
\hline fitting & - & - & - & - & - \\
\hline knowing & - & $\begin{array}{l}\text { knowledge } \\
\text { representation; } \\
\text { cultural knowledge }\end{array}$ & $\begin{array}{l}\text { knowing- } \\
\text { how-to-do }\end{array}$ & - & - \\
\hline learning & - & - & - & - & - \\
\hline memory & - & - & - & - & - \\
\hline modelling & - & - & - & $\begin{array}{l}\text { modeling } \\
\text { system }\end{array}$ & + \\
\hline representation & + & - & - & - & - \\
\hline resources & - & - & - & - & - \\
\hline scaffolding & - & - & - & - & - \\
\hline umwelt & + & + & - & /under \\
\hline
\end{tabular}

\section{Semiotic learning, memory}

Learning is a significant concept within a range of disciplines; not only those concerned with organic forms of learning (psychology, educational studies, anthropology, biology) but also technology-related fields (such as the study of artificial intelligence, and computer sciences) through the related notions of machine and computational learning.

A starting-point definition states that learning is the acquiring or modification of sign relations, which is manifest in a change of behaviour (see Stables 2005, 2006).

Recently, the concept of semiotic learning has become a significant cornerstone in biosemiotic, but also educational semiotic research. In these discourses, learning is linked with the growth of significance within a species-specific phenomenal world, or umwelt. Andrew Stables laid out the foundation for a semiotic educational philosophy and theory starting from the observation that "if all living is semiotic engagement, then learning is semiotic engagement" (Stables 2006: 375). This broad - and hermeneutically permissive - concept of learning has 
stimulated much semiotic inquiry on education recently (see Stables et al. 2018; Olteanu, Stables 2018; Campbell 2017; Olteanu, Campbell 2018).

Paul Bouissac, speaking about semiotics as the science of memory, has observed: "Considering that semiotics takes as its main object of inquiry systems of signs that are learned (languages, cultural codes, social discourse, etc.), it is surprising that so few semioticians so far have shown a marked interest in the science of memory" (Bouissac 2007: 76, emphasis added). Accordingly, together with the concept of learning, the concept of memory should also have a fundamentally semiotic definition. For instance: memory is the semiotic scaffolding established by learning. From this understanding, as we observe, "memory is not limited to the body of an organism. Traces in the surrounding, constructed niche, can be a part of memory" (Kull 2018: 458).

\section{Knowing, knowledge}

This overlap between the semiotic theory of education and the semiotic theory of biology reveals one of the most interesting features of semiotics in general: its implied theory of knowledge. Signs, as basic semiotic units, are not units of measurement, but rather refer to meaningful relationships that sustain, enable and constrain the organism's interactions - thus, they are ultimately qualitative and subject to dynamic change and growth. Notably, semiotic relations refer to an important type of "second order causality", that causes changes in the causal action itself, through altering the ways in which organisms re-channel energy (see Pearson 2018: 399-400; Campbell 2018: Section 5). Following trends in ecosemiotics and biosemiotics, it is possible to consider that semiotics itself is increasingly becoming a theory of knowledge, as it describes the diversity of models and modelling phenomena across different organisms' umwelten, and thus the "forms of knowledge" (Sebeok, Danesi 2000) expressed by life's diverse interactions. The interactions of living systems create new forms (scaffoldings and resources) for meaning-making. These basic biological forms (scaffolding structures) appear to be signs (or sign-vehicles) that organisms endow with meaning through coming to know them in their own species-specific ways. In this way, "biology accounts for a spectrum of meanings that a form affords within the horizon of an organism's competences for meaning-making" (Olteanu, Stables 2018: 411, emphasis added).

Defining semiotics as a theory of knowledge, of course, has a longer tradition. Tzvetan Todorov stated: "We are treating semiotics as a discourse whose objective is knowledge (rather than poetic beauty or pure speculation), and whose subject matter is the whole variety of sign phenomena (not only for example words)" 
(Todorov 1978: 1, emphasis added). This same idea is also referred to by Walker Percy (1957, "Semiotic and theory of knowledge"), Sandra Moriarty (2002: 25, "Peircean semiotics is a theory of knowing"), etc.

A principal and common feature of semiotic theories consists in their conceptualization of knowledge as interpretative. Both Charles Peirce's semiotics and the (post)structuralist tradition, inspired mostly by Ferdinand de Saussure's semiology, claim that knowing supposes interpreting. Semiotic theories, many of which can be conflicting in several regards, imply a hermeneutic epistemology (cf. Hoffmeyer 2018; Feil, Olteanu 2018). Also, meaning is to a large extent functional, as the pragmatic maxim states: meaning is in reference to some purpose, no matter how changing and dynamic such purposes may appear to be (CP 5.3 [1902]). In what regards behaviour, this semiotic view is complementary to, but also more encompassing than, that of cognitive dissonance theory in psychology (Festinger 1957).

We argue that a general semiotic theory of knowing can bridge logic and psychology while avoiding the pitfalls of subduing one to the other (e.g., Stjernfelt 2014). Cognition does not fit the narrow principles of formal, propositional logic; nor is logic necessarily psychological. Rather, a biosemiotic perspective asserts that phenomena like cognition, perception, and even consciousness, assume some primary semiosic operations that sustain these higher-level processes. Semiosis is a universal of cognition, expressed in the actions of any meaning-seeking system. The category of meaning, as foundational to semiotics, offers a perspective from which to understand learning outside of psychologic reductions, which mostly conceive of learning as the expression of achieved mental states or behavioural outcomes, ultimately occurring within the brain of the subject. From a semiotic account, meaning implies a relationship; this includes a mediating element that emerges through the pairedness of an organism's inside and outside (see Nöth 1998: 339). Thus, a semiotic theory of learning must ultimately be ecologically construed (Olteanu, Stables 2018; Campbell 2018, 2019), emphasizing the active abilities of organisms to reshape their environments through using and discovering sign-relations.

From a semiotic point of view, knowledge can be defined as everything meaningful. However, together with Jesper Hoffmeyer we add that "knowledge is not something we have but something created [evoked] in the very moment of use" (Hoffmeyer 2018: 1). Truthfulness is not a necessary condition for knowledge.

According to a semiotic model, meaning assumes mediatedness. Consequently, what may seem as direct knowledge (e.g. in the sense of Ingold 2019), in a closer analysis is revealed to include mediation. Mediatedness is a characteristic feature that distinguishes knowing from processes that do not include knowing (as occurring among non-living entities). 


\section{Semiotic resources}

From a semiotic perspective, resources and competences are complementary and inseparable concepts. A semiotic resource is something that can be used to represent; that can be engaged with semiotically and, as such, leads to the generation (or discovery) of (more) meaning. The concept of resources has roots in the Greimasian tradition of semiotics and is associated with the related notion of performances (cf. Pikkarainen 2018: 443) as the enacting of new active behaviour. The concept has mostly been investigated in social semiotics, in relation to the concept of modality that is used in communication and education (Kress, Leeuwen 2001; Kress 2003, 2010), and its applicability should be rather universal (Fei 2004). Semiotic resources, Kress considered, depend upon "the context of the choice of modes made" (Kress 2003: 8) within a new performance. The basic concept of semiotic resource supposes choice. Kress explained that because conveying something implies a representation of what is conveyed, the choices made in designing the representation are inherent in what is conveyed. The same holds true for learning: the way in which the learner perceives what is apprehended, its modalities of expression, is an inherent part of the apprehension. Knowledge, this is to say, is a matter of design. The idea behind Kress' construal of resource as a matter of modal choices is also expressed, in a biosemiotic concern, in Hoffmeyer's explanation that information is meaningful only by its framing in a medial context (Hoffmeyer 2018: 5).

The social semiotic approach, however, tends to ignore the role of the body in knowledge and communication. Semiotic resources are here deemed as anything "available in a culture" (Kress, Leeuwen 2001: 4) that can be used for meaningmaking. We extrapolate and expand this notion of semiotic resource to encompass not only resources for meaning-making within a culture, but available in the environment, in general. The need for an embodied account of meaning is evident not only in a biosemiotic concern. For instance, Elleström (2018: 270-271; 2019: 10) argues that mediality, as the intermediate stage of communication, is not evoked only by culture or technology but, to begin with, by an organism's body. Besides the need for an embodied perspective on meaning (and knowledge), this also avoids the cultural atomism and exaggerated relativism implied, on some accounts, in social semiotics (e.g., Kress 2010: 19) by anchoring learning in specific linguistic and cultural modes (see Cobley 2016; Olteanu 2019). As we explain in more detail below, this comprehensive notion of semiotic resource connects with that of affordance, as coined by Gibson (e.g., 1979). The relation, mostly morphological, between body and landscape affords certain resources. Thus, semiotic resources are not merely anything present in the environment, but anything that an organism's sense perceptive and motoric capabilities evoke as available. 
Semiotic resources are subjective, depending on (1) what the organism, given its embodied morphology and its relation to the environment, can use and (2) what the organism chooses to use. For instance, a tree can be used for nesting by a bird and as source of food for a monkey. However, the monkey could additionally come to choose to use the tree as shelter. A human might choose, also, to use the same tree as fuel. All these uses are based on (almost) the same "hard" physical matter, but they rely on different resources, conceived semiotically.

\section{Semiotic competences}

According to Stjernfelt (2006), the (post)structuralist tradition of semiotics tends to regard the body as yet another cultural concept, represented in culturaldependent modalities, being conceived "as subjected to the free arbitrariness of semiotic systems - and no special attention would be paid to the body as a crucial prerequisite of semiotic articulation" (Stjernfelt 2006: 14). This mentalistic view dissociates what evokes learning from what limits it, as "no extrastructural constraints are supposed to determine the spectrum of possibilities of body representation" (Stjernfelt 2006: 14). In view of the various pathways that contribute to biosemiotic theory, such as Jakob von Uexküll's (1982[1940]) theoretical biology, cognitive semantics (Lakoff, Johnson 1999; Fauconnier, Turner 2002), Merleau-Ponty's (1995) phenomenology of the body, and complexity theory (Kauffman 2000), Stjernfelt sets the direction for developing a body concept that "makes evident the basic semiotic competences of an organism, i.e., a body concept which entails semiotics" (Stjernfelt 2006: 14, emphasis added).

With this claim, Stjernfelt also places the notion of semiotic competence in the new light of embodiment theory. In contradiction to the dualist view of the body as the external shell of an intelligent mind, where the latter is responsible for knowledge, the body itself is conceived as epistemological. Thus, the body is not defined as a brute physical form, constituted merely by joint limbs and component parts, but in relation to the competences for meaning making that this biological form entails.

From this perspective, we define semiotic competence as the capability of an organism, dependent on its embodied morphology, to discover meaning resources in a given environment and to recombine them in new, pragmatically functional models. As such, semiotic competences are employed to scaffold knowledge, which is to say, to develop models of (aspects of) their environment, which result in a capacity to navigate in the environment. A scaffolding is similar to what it aims to grasp, being deemed a model, because, following this metaphor for learning, 
it moulds onto it. ${ }^{6}$ The erection of new scaffoldings, thus, leads to environmental changes that evoke new semiotic resources. In the scaffolding process, not only organisms change - their environments change, too. Thus, as new semiotic resources become available and are used, organisms and environments co-develop.

This notion of semiotic competence critically differs from the traditional conception as merely a more encompassing version of the concept of literary competence (see Culler 1980: 109-110), stemming from Chomskyan linguistics and, further down the line, from Saussure's semiology. Rooted in linguistics, these accounts of competence are precisely the target of Stjernfelt's (2006) criticism, as they imply a view of the body as entirely subjected to cultural and linguistic arbitrariness and, thus, not responsible for knowledge (see also Olteanu, Stables 2018: 425). ${ }^{7}$

\section{Affordances: an evolving concept}

\subsection{Gibson's conception}

The American psychologist James Gibson coined the concept of 'affordances' through his project of developing an "ecological approach" to the study of visual perception. Gibson marked this a theory of direct perception, in distinction to theories that assert that perception is mediated (i.e., through mental representations, models, cognitive schemas, etc.). ${ }^{8}$

6 See René Thom's and Thomas A. Sebeok's view of competence, as discussed in the context of iconic learning and educational semiotics, in Campbell (2019: 300-304).

7 A related notion of competences (also linguistically derived and expressed) has significantly entered curriculum discourse and policy in the last two decades (see, for example, Ruitenberg 2019). In these discourses, competences basically refer to pre-determined benchmarks for educational success that learners and teachers are expected to "perform" (see Stables 2019: 27-30, for this "problem of performativity" in education). As Biesta and Priestley observed in their classic article "Capacities and the curriculum": "what is significant here is that [...] the student shifts from being the subject in education - that is the one who is supposed to study, learn, master, acquire, evaluate, judge, etcetera - to become the outcome of education" (Biesta, Priestley 2013: 36). It is hypothesized that an embodied and ecological, meaning-based notion of competences (as presented in this study) may open new avenues for philosophically refining "competency-talk" in educational research and curriculum design.

8 Chemero (2006: 59-60, emphasis added) describes the three main tenets of Gibsonian direct perception cogently: "First, perception is direct, which is to say that it does not involve computation or mental representations. That is, Gibson thought that perception was not a matter of internally adding information to sensations. Second, perception is primarily for the guidance of action, and not for action-neutral information gathering. We perceive the environment in order to do things. The third tenet follows from the first two. Because perception does not involve mental addition of information to stimuli, yet is able to guide 
Over the course of his career, Gibson increasingly found classic empirical psychology generally inadequate for understanding the complexities of perception, as it did not account for an actor's actual engagement and immersion in their environment: "[...] orthodox psychology asserts that we perceive [...] objects insofar as we discriminate their properties or qualities" (Gibson 1979: 134). Instead, he proposed "that what we perceive when we look at objects are their affordances, not their qualities" (Gibson 1979: 134, emphasis added). Thus, he introduced the novel term "affordance" that implies an ecological dimension for learning:

The affordances of the environment are what it offers the animal, what it provides or furnishes, either for good or ill. The verb to afford is found in the dictionary, but the noun affordance is not. I have made it up. I mean by it something that refers to both the environment and the animal in a way that no existing term does. It implies the complementarity of the animal and the environment. (Gibson 1979: 127 , emphasis in original)

This concept was in many ways Gibson's last main contribution to the theory of visual psychology that he had been developing since the publication of his first book The Perception of the Visual World (1950) and culminating in the posthumous, The Ecological Approach to Visual Perception (1979), where the notion of 'affordances' is presented and developed. Gibson believed that visual psychology could no longer proceed from the dualistic basis of a "depersonalilzed" operational environment, conceptualized as distinct from the organism's cognized environment (see D'Aquili et al. 1979 for the distinction). Although it is possible to model aspects of the environment through a physicalist lens, Gibson stressed that "this is not to say that it [an organism] perceives the world of physics and behaves in the space and time of physics" (Gibson 1979: 8). On account of this non-dualist and phenomenal approach we consider that Gibson's affordance theory can be insightfully coopted in the scope of (bio)semiotics.

When considering how the environment affords possibilities for action and response, the organism's embodied, species-specific phenomenal world (umwelt) is of central importance. ${ }^{9}$ Gibson stressed that the organism must always be considered in terms of its embeddedness within an eco-system; as even its sense organs and perceptual systems evolved in intimate connection to a local and

behavior adaptively, all the information necessary for guiding adaptive behavior must be available in the environment to be perceived." See also Michaels, Carello (1981: 2) and Fodor, Pylyshyn (1981) for more on the importance of this distinction for psychology.

9 "[The physical properties that constitute affordances] have unity relative to the posture and behaviour of the animal being considered. So, an affordance cannot be measured as we measure in physics" (Gibson 1979: 127-128). 
dynamic environment (cf. Gibson 1966). In a semiotic manner, the organism's embeddedness within an ecosystem can be regarded as long processes of scaffolding, which, in most cases, started long before the organism's individual birth and is continued by the individual organism's environmental modelling, in ways critical for its own existence. This idea of embeddedness led Gibson to an important reimagining of the concept 'niche' as "a set of affordances" (Gibson 1979: 128). ${ }^{10}$

\subsection{Limits of Gibson's concept}

As the above passages indicate, central to Gibson's conception is that affordances are not solely in the environment or the organism, but rather, cut across the subjective-objective barrier. Nevertheless, it is precisely this complementarity that has given rise to ambiguity in Gibson's own use of the term and has resulted in the concept being frequently critiqued and reformulated (cf. Shotter 1983; Stoffregen 2000; Scaratino 2003; Costall 2012; Dotov et al. 2012; Barsingerhorn et al. 2012: 55). For example, Gibson often seemed to suggest that affordances are fully on the side of the environment, and thus more (ontologically) "real" than purely meaning-based (semiotic) relations. ${ }^{11}$

By not focusing on the ontological status of affordances, and dealing mainly with the perception of ambient light, Gibson could sidestep the complicated problems around how an actor's experience (personal and cultural) impacts upon the perception of affordances. Gibson stated this explicitly: "The central question for the theory of affordances is not whether they exist and are real but whether information is available in ambient light for perceiving them" (Gibson 1979: 140). The result: the awkward line that Gibson is forced to walk because of this evasion, is empirically vague and philosophically muddled. We aim to invest the concepts of 'niche' and 'affordance' as inspired from Gibson, in sharper focus by nesting them in a semiotic framework, where body and environment are revealed as co-developing.

10 "A species of animal is said to utilize or occupy a certain niche in the environment. This is not quite the same as the habitat of the species; a niche refers more to how an animal lives than to where it lives. I suggest that a niche is a set of affordances [...]. The natural environment offers many ways of life, and different animals have different ways of life. The niche implies a kind of animal, and the animal implies a kind of niche. Note the complementarity of the two" (Gibson 1979: 128). Cf. the concept of semiotic niche in Hoffmeyer (2008: Ch. 6).

11 "An important fact about the affordances of the environment is that they are in a sense objective, real, and physical, unlike values and meanings, which are often supposed to be subjective, phenomenal and mental. But, actually, an affordance is neither an objective property nor a subjective property; or it is both if you like. An affordance cuts across the dichotomy of subjective-objective and helps us to understand its inadequacy" (Gibson 1979: 129). 


\subsection{Connections to umwelt}

As evidenced by the widespread use of the term in many disciplines, the power in Gibson's concept resides precisely in its broad generality, not its narrow applicability within visual psychology. ${ }^{12}$ As testament to this, many scholars have suggested that more heuristic value can be returned to Gibson's concept by embedding it within Jakob von Uexküll's theory of umwelt. ${ }^{13}$

Tim Ingold (2009; also 2000) in particular has closely compared the relationships between the two concepts. Despite Gibson having set out to develop an ecological conception that always maintains complete complementarity of observer and environment, ${ }^{14}$ he eventually contradicted himself by ultimately placing affordances firmly on the side of the environment, even making incompatible statements like "the environment does not depend on the organism for its existence" (Gibson 1979: 8, 129). Ingold (2009: 144) concludes by affirming how the philosophical conviction behind statements such as these are ultimately incompatible with the active functional meaning-seeking system referred to through Jakob von Uexküll's umwelt concept:

For whereas Gibsonian affordances are supposed to exist as the inherent potentials
of environmental objects, regardless of whether they are attended to or put to use
by any organism, von Uexküll maintained that what he called the 'quality' (Ton)
of a thing, by virtue of which it has significance for a particular creature, is not
intrinsic to the thing itself but is acquired by virtue of its having been drawn into
that creature's activity (Uexküll 1982: 27-29). (Ingold 2011: 79)

Ingold goes on to draw upon classic examples from umwelt theory, which are also interrelated with our re-definition of semiotic scaffolding in this article: a stone in a river can function as a habitat for a crab, a hard surface for breaking shells for gulls, and a stepping-stone for a bridge for a human:

In Gibson's terms [...] [these] are all properties of the stone that are available to be taken up. For von Uexküll, by contrast, they are qualities that are bestowed upon

12 As Dotov et al. (2012) point out, a notable influence of Gibson's concept came directly and indirectly from the American pragmatist tradition, which Gibson was a part of through his adviser Edwin Holt who himself was a student of William James. For more about the influence of pragmatist philosophy on ecological psychology in general, see Heft 2001.

13 See for example: Cunningham 1988, 1998; Ingold 2009; Dotov et al. 2012. Uexküll even had his own notion of affordances within his approach to ethology, in his concept of 'functional tone' (funktionale Tönung).

14 The "subjective world" (Gibson 1979: 129) perspective that Gibson recognizes as being present in the work of certain biologists, without specifically mentioning or citing Uexküll. 
the stone by the need of the creature in question and in the very act of attending to it [...]. Thus, far from fitting into a given corner of the world (a niche), it is the animal that fits the world to itself by ascribing functional qualities to the things it encounters [affordances] and thereby integrating them into a coherent system of its own. (Ingold 2009: 144-145)

Ingold concludes that the concept of affordances is enriched when embedded within this corollary concept of umwelt, in place of more static designations such as environment and niche; helping to maintain the holism that Gibson sought but was ultimately unable to fully articulate.

When in recent work Ingold preferred the concept of affordances to the concept of umwelt, he used an argument that affordances (as different from umwelt) provide unmediated direct knowledge (Ingold 2019). This is obviously due to a narrower concept of mediation used by Ingold; according to biosemiotic accounts, any perception includes mediation. ${ }^{15}$

Donald Cunningham $(1988 ; 1998)$ has proposed the affordances-umwelt coupling for educational psychology and developing semiotic theories of learning. Despite occasional forays into the term's applicability within semiotic studies (cf. Windsor 2004), 'affordances' has been relatively underexplored in general semiotic discourse $^{16}$ - at least compared to the extensive use of the term within social semiotic and other applied forms of semiotics.

As noted by Niveleau (2006), affordance stems from the concept and philosophy of gestalt and forgetting this connection has impoverished the concept of affordance.

\subsection{In technology, social semiotics, music}

As alluded to, the concept of 'affordances' has been widely adopted within technology studies and design-oriented fields (e.g. Faraj, Azad 2012; Majchrzak et al. 2013; Treem, Leonardi 2013). It is important to note that in large part the concept entered these discourses through Donald A. Norman's repurposing of the term in his design classic The Psychology of Everyday Things (1988). In contrast to Gibson's earlier formulation that stressed non-dualistic complementarity of subject-object relations, Norman's notion is entirely (and deliberately) dependent

15 Even signal transduction requires mediation (Bruni 2008). For instance, the mediating element is described by Barbieri as code-maker.

16 Winfried Nöth (2010) has compiled a valuable and thorough literature review of educational semiotics, or edusemiotics as it is sometimes referred to. Gibson's concept of affordances and its use in semiotic discourses is briefly discussed in a section on ecological semiotics, a field Nöth himself has been an important pioneer of. 
upon the competence and capability of the actor. ${ }^{17}$ Unlike much subsequent research in technology and even multimodality studies, Norman fully acknowledges this distinction between his concept of affordance and that of Gibson's. ${ }^{18}$

As McGrenere and Ho note, the main difference between the two conceptions is that for Gibson, affordances are "action possibilities in the environment in relation to the action capabilities of an actor" and for Norman, they are "perceived properties that may not actually exist" (McGrenere, Ho 2000: 181). As for Gibson, for Norman, too, the ontological status is ultimately irrelevant, but now the notion has been inverted, in part. Notably, it is the interpretation and linage of the term within design that seems to have informed Kress and the New London Group's concept of 'modal affordance' as "what it is possible to express and represent easily (within a given cultural mode)" (Jewitt 2008: 247). ${ }^{19}$

Interestingly, the concept has also significantly entered music-related disciplines (music cognition and perception studies, music education studies), from other related educational discourses (e.g. López Cano 2006; Menin, Schiavio 2012). Some recent music-related research that has significantly developed the concept of affordances has turned to biosemiotic theory and explanations. This includes a neo-Peircean 'biosemiotic' reading of how music emerged in the human species, from evolutionary musicologist Gary Tomlinson (2015; cf. Schyff, Schiavio 2017), and a biosemiotic account of musical perception and cognition that places both umwelt and affordances in a central role, in the work of Reybrouck $(2012,2015)$.

17 “[...] the term affordance refers to the perceived and actual properties of the thing, primarily those fundamental properties that determine just how the thing could possibly be used. [...] Affordances provide strong clues to the operations of things. Plates are for pushing. Knobs are for turning. Slots are for inserting things into. Balls are for throwing or bouncing. When affordances are taken advantage of, the user knows what to do just by looking: no picture, label, or instruction needed" (Norman 1988: 9).

18 As an important footnote puts it: "The notion of affordance and the insights it provides originated with J. J. Gibson, a psychologist interested in how people see the world. I believe that affordances result from the mental interpretation of things, based on our past knowledge and experience applied to our perception of the things about us. My view is somewhat in conflict with the views of many Gibsonian psychologists, but this internal debate within modern psychology is of little relevance here" (Norman 1988: 219).

19 The term had made its way into educational discourse long before Kress and his colleagues took it up (largely in the fields of educational psychology, science and engineering education, music education). Two points should be noted: first, that usage of the term in educational discourses picked up as the 1990s progressed, although it had been used as early as 1984, and second, the majority of the articles explore the concept from within a "designs for learning" perspective. 


\subsection{Extending affordances into general semiotics}

The issue of how far we may comfortably extend this notion of affordances into the cultural and social realms is of central importance for our re-definition within a general (bio)semiotic framework. This issue has been the subject of vociferous and frequent debate in the Journal for the Theory of Social Behaviour, particularly through the 1980s and 1990s. Ginsburg (1990) offers an extensive review of this scholarly conversation, and emphasizes that the diversity of often contradictory views on affordances is in large part the result of Gibson's own "conceptual temerity" around how to best deal with cultural or social perception. This was no doubt due to Gibson's own convictions that direct perception, unmediated by language, or any sort of representational content is the "simplest and best kind of knowing" (Gibson 1979: 263). As Noble (1981, 1991) and Heft (1989, 1990, 2001) do well to note, ultimately this conviction results in Gibson having: (1) conceptualized affordances as almost solely environmental properties, and (2) undermined the role played by the organism's (potential) actions in detecting and perceiving affordances (in brief, the organism's freedom).

This debate directs us to take a semiotic view on affordances, in which, as Sanders (1997: 108, emphasis added) states, "affordances are opportunities for action in the environment of an organism, the opportunities in question include everything the organism can do, and the environment includes the entire realm of potential activity for that organism [...]". Luke Windsor, a musicologist, extended this debate into general semiotics by emphasizing that when considering affordances, no distinction between direct and indirect perception is required: "the perception of a semiotic affordance is just as direct as the perception of an affordance of any event or object, given that one accepts that cultural aspects of the environment provide us with affordances at all" (Windsor 2004: 189). He explains how Peirce's triadic sign model allows for the conceptualization of affordance as a changing mediation, between (a) stimulus information, (b) unfolding events in the environment, and (c) action-possibilities for the actor. Windsor (2004: 193) explains that "the organism and environment are brought into a meaningful relationship by perceiving and acting upon affordances. However, affordances are a description of the relationship between organism and environment, not the means by which organism and environment become coupled." This suggests that affordances are potential (as yet, unactualized) action-possibilities; and thus, ultimately sign-relations, whose meaning emerges in reference to an evolving function (a means) ${ }^{20}$ and in use (CP 5.569).

20 "The action of the organism "interprets" this causal relationship to create the possibility of meaning through a "third". Stimulus information, events and actions are the necessary components for describing affordances, and no pair of these terms provides a sufficient explanation of perception" (Windsor 2004: 194). 


\subsection{Redefinition}

As for our redefinition within a general semiotic theory of knowing, we place affordances in close connection to the semiotic construal of learning: we propose defining affordances as potential semiotic resources that an organism enacts (detects, reads, uses, engages) to channel learning-as-choice in its environment. Like Gibson (1966: 285), Windsor emphasized that "learning is vital to the perception of affordances" (Windsor 2004: 189). We follow Windsor, but also further highlight that the organism's ability to make use of these resources in meaningful ways is dependent upon its species-specific embodied competences.

Further, to account fully for the implications of this definition, we emphasize that in invoking and enacting these affordances, organisms make use of and enact scaffolding structures and processes. These scaffolding processes direct and focus decision-making, expressed through learning.

\section{Scaffolding}

\subsection{Scaffolding in educational studies}

The concept of scaffolding stems from the socio-constructivism of Lev Vygotsky who introduced the idea but did not himself use the term (see Vygotsky 1986 [1934]). ${ }^{21}$ The concept was first significantly developed by Jerome Bruner and his colleagues in Wood, Bruner, Ross 1976 to help explain how adults interact with children in joint problem-solving activities. Put very generally, scaffolding is used as a conceptual metaphor in the learning sciences - explaining a developmental and pedagogical process or strategy by which temporary support (in a broad sense) is given to learners to aid them through tasks and activities they might not otherwise be able to complete or undergo independently (Pol, Volman, Beishuizen 2010: 271-272). Cazden (1979) early on connected the concept with Vygotsky's zone of proximal development (ZPD). The ZPD refers to a liminal developmental space; between what a learner can do on her own and what she cannot yet do. As described by Vygotsky: "[...] the distance between the actual developmental level as determined by independent problem solving and the level of potential development as determined through problem solving under adult guidance or in collaboration with more capable peers" (Vygotsky 1978: 86; see also Olteanu, Campbell 2018: 253-254).

21 Although, Vygotsky and Luria (1930: 202) occasionally used the scaffolding metaphor (see Veer, Valsiner 1991: 226). For the early history of the scaffolding metaphor see Shvarts, Bakker (2019). 
Pol, Volman and Beishuizen (2010) explain in their review of "Scaffolding in teacher-student interaction", that despite the term being well used in the learning sciences, there remains no common consensus on its definition. Many authors have argued that "the concept of scaffolding has been applied too broadly in educational and psychological research" (Pol, Volman and Beishuizen 2010: 272) to the extent that it "has become unclear in its significance" (Pea 2004: 423). ${ }^{22}$

\subsection{Interdisciplinary scope and use in biosemiotics}

The term 'scaffolding' has recently received significant transdisciplinary attention. ${ }^{23}$

Notably, the concept has been developed and used within biosemiotic research within the last 15 or so years: see, in particular, Hoffmeyer 2007, 2014a, 2014b, 2015, Kull 2012, 2014, 2015, and Fernández 2015a, 2015b.

In these studies, it seems to be precisely the term's broad generality that is valued; providing explanatory power in understanding biological and semiotic evolution non-deterministically. Semiotic scaffolding is closely linked with a concept of learning, describing how organisms continually seek and extract meanings through their interactions within their umwelt.

The term has become a central theme within Jesper Hoffmeyer's post 2005-work (noted in Kull 2015: 224). The following description from Hoffmeyer highlights the broad scope of the concept for biosemiotics, and its connections to semiotic conceptions of embodiment: "The network of semiotic interactions by which individual cells, organisms, populations, or ecological units are controlling their activities can thus be seen as scaffolding devices assuring that an organism's activities become tuned to that organism's needs" (Hoffmeyer 2007: 154). From Hoffmeyer's research on scaffolding two main points become clear: "(1) scaffolding in its exact sense is always a semiotic scaffolding, and (2) semiotic scaffolding is at work in all levels of semiosis, from the origin of life forward" (Kull 2015: 224).

\footnotetext{
22 At its most general, scaffolding seems to be used as a metaphor for any kind of instructional support (Puntambekar, Hübscher 2005) and many authors have critiqued its utility: see Butler 1998; Donahue, Lopez-Reyna 1998; Scruggs, Mastropieri 1998, and the discussion in Pol, Volman, Beishuizen 2010: 274-276. For defenses of the scaffolding metaphor, see the work of Stone (1993, 1998a, 1998b).

23 Within the philosophy of science, to describe the growth and construction of scientific theories and knowledge and the process of cultural evolution (Wimsatt, Griesemer 2007; Wimsatt 2014); a notion of language as scaffolding within embodied cognition discourses (Clark 2008). The term has also received focus from recent research in theoretical biology (see Caporael, Griesemer, Wimsatt 2014). See also the connection to models as scaffolds of understanding in Shank et al. 2014.
} 


\subsection{Scaffolding defined through learning}

What makes scaffolding properly semiotic must have to do, ultimately, with the kind of learning evoked. ${ }^{24}$ As explained by Kull $(2015 ; 2018)$ - but also Campbell (2017, 2018) - semiotic learning is different from computational learning, for "semiotic learning requires a choice between options" (Kull 2015: 225). It requires decision-making and "decision making is not computing, it is choice" (Kull 2015: 226). Choice, as meant here, is phenomenological: decisions are situated, taken by organisms in timespace. Problems that require solving are not laboratory simulations or the playing-out of algorithms. They are real events, with existential consequences for sentient beings, unfolding in organisms' umwelten. Semiotic learning through choice requires two elements: (1) a situation of logical incompatibility, in which a problem-situation emerges for the organism, and (2) a phenomenal present (or species-specific nowness), "a subjective duration felt as one moment so that the options or choices, which computationally taken are always sequential, are seen simultaneously" (Pikkarainen 2018: 444). This choice may prove in the future to be adaptive, in the sense that it may come to make the organism's needs more aligned with its actions in the environment. Through such processes the organism sets new scaffoldings (semiotic, but with "real" environmental effects) to channel knowing in the environment. These scaffolding structures would not be there if the "correct" decision was taken to begin with ( simply encoded in the environment, or in the organism's brain and body structure, as exemplified in our above discussion on affordances). This highlights the importance of the learning process itself, suggesting that in life, there are no shortcuts to knowledge - knowledge and knowing are something that must grow with and within the organism. While there are no shortcuts, in a sense, neither are there detours: continuous learning-through-time unavoidably evokes learning, which is how we interpret Peirce's daring statement that, while denying the old empiricist tabula rasa doctrine, "experience is our only teacher" (CP 5.50).

Understanding learning and living as co-extensive with meaning-making means that knowledge, and the study of it, takes on an existential dimension. To live is to learn (or know) about the world through the scaffoldings of previous experiences and previous generations (at biological, cultural and personal levels). Such scaffolding is enacted according to an organism's species-specific competences and to how these function adaptively within a historically dynamic environment.

24 Kull (2014: 118) observes how different mechanisms of learning result in the formation of different types of sign relations: "(a) relation of recognition - iconic signs; (b) relation of association - indexical signs; (c) relation of imitation - emonic signs; (d) relation of convention symbolic signs". 
To recap: through evolving modes of semiotic engagement (Stables 2006), particular challenges (or problem-situations) arise for an organism; and through these, also new opportunities and affordances. Some of these problems/opportunities are reoccurring and thus generalizable; others are more indeterminate and novel. These problems require responses, and through a process of learning-overtime organisms create and enact varying types of "scaffolding" to channel learning adaptively: "Due to scaffolding, the choice becomes directed" (Kull 2015: 226).

Learning requires both some degree of incompatibility (code plurality), as well as constraints and direction (that is, scaffolding). As noted by Kull (2015: 227): "Semiotic scaffolding provides direction, while code plurality provides incompatibility for choice. The reason why scaffolding provides direction is because it is built of links that are earlier products of choice, of the decisions made". This is to say that for 'learning' to be learning at all, it cannot be singular and occasional. Learning requires memory (Kull 2018: 458; Campbell 2019:301-304), a trace, so that a related problem can be solved in a less unpredictable way in the future:

[...] what we call scaffolding is the means that supports decision making and learning. It is that which, in the situation of indeterminacy, provides certain preferences in making decisions. Also, under scaffolding we mean the kind of structures that carry traces of some earlier like, that has been built by life, by semiosis. (Kull 2015: 229, emphasis added). ${ }^{25}$

This allows for the explanation that "what appears as adaptation, has gone through this kind of stage of problem-solving" (Kull 2015: 225), and thus scaffolding refers to an important but, arguably, neglected aspect of the evolutionary process. ${ }^{26}$

25 This points to a difference with educational studies. Unlike its characterization, for example, in Pol, Volman, Beishuizen 2010: 277, who insist that scaffolding is a combination of certain scaffolding means with certain scaffolding intentions, in biosemiotics, by focusing on the "means" of scaffolding, we can better understand the structural aspects of this general process, while recognizing that, in a certain sense, the intentional aspects of scaffolding at the biological level are provided by the teleological aspects of the life process itself.

26 Fernández (2015a: 91-92, emphasis added) says, that biosemiotics itself is an attempt "to organize and reconceptualize our knowledge of living systems, their functions, origins and evolution, in terms of the crucial role played by semiotic causation and semiotic scaffolding in practically every aspect of their internal dynamics (i.e., energy and nutrients acquisition, metabolism, reproduction, etc.) as well as in their complex energetic and semiotic interchanges with their surroundings". 


\subsection{Redefinition and integration with other general semiotic concepts}

The notion of semiotic competence that we present in this article is also closely related and, more precisely, explicative to our definition of scaffolding. Semiotic competence (see above) here consists in the organism's ability to activate semiotic resources in the form of affordances (see Kull 2018: 459; Olteanu, Stables 2018: $423,429)$. This ultimately manifests itself as an anticipatory response; by which a relationship to a 'possible future state' reconfigures the organism's current state of being (Campbell 2017; 2018; Nadin 2017; Hoffmeyer 2007: 149). This anticipatory competence is always "based on the constraints established or modified in learning" (Kull 2018: 45). Thus, affordances as potential resources are themselves "a result of earlier traces and choices that reappear during the recognition event" (Kull 2018: 45). Through a recursive process of discovering sign relations in the environment and gradually canalizing these action-habits into scaffolding, organisms achieve new semiotic competences or, more directly, they learn: "[Scaffolding] is the frame for the formation of future habits" (Kull 2015: 232).

As emphasized in both educational and semiotic studies (see Wood, Bruner, Ross 1976: 98; Bernstein 1967; Kull 2014: 116), scaffolding imposes and enacts constraints that - like the recursive process of semiosis itself - simultaneously narrow interpretative possibilities while revealing new ones (in the form of affordances). Hoffmeyer (2015: 251-252), explained that through such lens we can think of cultural institutions as scaffolding structures, that channel learning in a particular way: "Each new jump to higher level semiotic scaffolding systems tends to homogenize cultural performances at the lower level while opening up new agendas of expressivity at the higher level". ${ }^{27}$

These tendencies are prevalent in what is commonly called learning, which can be said to proceed through a process of (1) singularization, closing and narrowing meaning-possibilities, and (2) diversification, which introduces new distinctions and thus new codes and code incompatibility (Kull 2014: 117).

When scaffolding is able to channel effectively learning in an umwelt, new habits and also new codes arise. At this stage, it is important to distinguish between the concepts of scaffolding and code. What distinguishes codes from scaffolding, is their functionality; code refers to a binary sign-relation, defined through correspondence, "whereas scaffolding always has a supporting task or function" (Kull 2015: 230). We can clarify each in relation to the another: "[...]

27 We see these principles at work in how representational systems (notation, languages) both close and open communicative possibilities. See, for example, the analysis of the effects that musical notation and symbolic cognition have on music perception and learning in Reybrouck 2015. 
semiosis is a learning process that produces scaffolding that forms habits that results in codes" (Kull 2014: 116, emphasis added). The process of habituation refers primarily to transformations at the agent level - and this is perhaps how we may distinguish habit from scaffolding, which refers more specifically to a continuing process that necessarily involves at least several agents and a supporting (i.e. collaborative and in a sense pedagogical) function.

As regards scaffolding, Hoffmeyer (2010: 196) postulated that "one of the few general trends that can be ascribed to organic evolution is the tendency towards the production of species exhibiting more and more semiotic competence or freedom in the sense of locally meaningful interpretants". Such an increase in semiotic freedom can be described as the growth in the logical richness of decisionmaking.

Semiotic freedom refers here to the complexity of choice an organism has for channeling learning in a way that sustains meaningful relationships within its umwelt (see also Stjernfelt 2006: 23). This is not necessarily or simply an increase in choice, but rather growth of meaning. As Peirce posited, "And what is growth? Not mere increase!" (CP 1.174). ${ }^{28}$

Of course, the diversity of semiotic resources at an organism's disposal is related to the faculty of re-cognition, and thus the competency in interpreting a depth of meaning, so that the same form or event ${ }^{29}$ can be variously interpreted for example, one may identify the same sign as quality (icon), as referent (index), as convention (symbol). However, such variability is not necessarily by default evolutionary advantageous for organisms with very different bodily structures (such as plant and fungi life). Divergent umwelten require divergent solutions; to learn is to find solutions that work locally and immediately.

\section{Conclusion}

A semiotic account on learning (and its various descriptive elements and concepts: competence, resource, affordance, scaffolding) shows the need for a broader ecological perspective, where the eco-system itself is recognized as central to how the organism forms meaning within its umwelt. As Nöth shows, the biosemiotic

28 For more details see Hoffmeyer 2015: 251. Campbell (2018: 563) explains this notion of semiotic freedom through reference to the etymological origins of the English word learning in 'leornian', which has base roots in 'to follow or find the track', saying: "A growth in semiotic freedom is inevitably expressed in the capacity of an organism to model its environment in its own species-specific manner; to learn (to "find the track") within its umwelt".

29 See Stjernfelt's (2006: 23-24, 33-34) concept of 'neutral object'. 
notion of umwelt implies that organisms model their environments by an uninterrupted, subjective hermeneutic circle (Nöth 1998: 339). We identify this hermeneutic circle with the interpretive framework, understood as evolving, which according to Stables both enables and constrains knowledge. More precisely, the hermeneutic circle enables knowledge by restricting it, by framing it within what Peirce, inspired by Augustus de Morgan (1840), termed the "universe of discourse" (CP 2.517). This is what is ultimately described through semiotic scaffolding: "[...] organisms would hardly be able to make reasonable decisions without their bodies together with their ecosystems embedding earlier experience helping them to direct their future choices" (Kull 2015: 232). Scaffolding is thus central in contributing to an account of development and learning that puts these qualitative features (such as support, environment-organism interaction, and collaborative learning) into focus: a reminder that learning is enacted from within the unfurling event of semiosis (Campbell 2018).

Like the concept of affordances, scaffolding also refers to a mediation. It is in this sense, that we can say that "semiotic scaffolding is what makes history matter to an organism (or a cultural system)" (Hoffmeyer 2015: 154). This basic emphasis on complementarity is highly compatible with Peirce's conviction that signs play a central role in what is now called cognition, to the extent that "externalized signs are not mere supportive devices, instead, they undertake tasks which simply could not be performed by the brain (or body) alone" (Peirce as paraphrased in Hoffmeyer 2015: 252; cf. CP 7.364). This synthetizes this article's proposal for a general semiotic account of knowing, that redefines psychological and cognitive conceptions without reducing them to mentalistic or computational explanations. ${ }^{30}$

Defining learning as the growth or modification of sign relations eschews reductively cognitivist or computational accounts.

For a semiotic theory of knowing, what is important is what things mean for the organism. Because this meaning grows over time, it must be accounted for through criteria of semiotic fitting (Kull 2020). Every choice is an opening and a closure, and to know is to occupy a place within a vast network of semiotic entanglements within an environment and ecosystem. This emphasises both the ecological and phenomenological dimensions of a semiotic theory of knowledge: "Knowledge acquisition is based on new relations being established by the learning system itself” (Kull 2015: 232).

30 Olteanu and Stables (2018: 421) explain: “[...] from its beginning, biosemiotics was defined by Sebeok [e.g. 1991, 2001] [...] as a modelling theory and, while useful for cognitive theories as well, it does not impose any particular assumption about cognition. Thus, from this perspective, a theory of learning does not necessarily imply a discussion on cognition. An educational theory and system can conceive learning in terms of signification only". 
In brief, our argument is that the semiotic toolbox can be greatly expanded by linking concepts that describe cognitive processes to the concept of semiosis via their updated definitions, because cognitive processes are naturally semiosic. Semiosis as the basic meaning-making process grounds learning and knowing.

Extending the list of semiotic concepts is part of a larger programme in the development of semiotic theory. ${ }^{31}$

\section{References}

Barsingerhorn, Annemiek D.; Zaal, Frank T. J. M.; Smith, Joanne; Pepping, Gert-Jan 2012. On possibilities for action: The past, present and future of affordance research. Avant 3(2): 54-69.

Bernstein, Nikolai A. 1967. The Co-ordination and Regulation of Movements. Oxford: Pergamon Press.

Biesta, Gert; Priestley, Mark 2013. Capacities and the curriculum. In: Priestley, Mark; Biesta, Gert (eds.), Reinventing the Curriculum: New Trends in Curriculum Policy and Practice. London: Bloomsbury, 39-50.

Bouissac, Paul (ed.) 1998. Encyclopedia of Semiotics. New York: Oxford University Press.

- 2007. Semiotics as the science of memory. Sign Systems Studies 35(1/2): 71-87.

Brandt, Per Aage 2020. Cognitive Semiotics: Signs, Mind and Meaning. (Bloomsbury Advances in Semiotics.) London: Bloomsbury Academic.

Bruni, Luis Emilio 2008. Cellular semiotics and signal transduction. In: Barbieri, Marcello (ed.), Introduction to Biosemiotics: The New Biological Synthesis. Dordrecht: Springer, 365-408.

Butler, Deborah L. 1998. In search of the architect of learning: A commentary on scaffolding as a metaphor for instructional interactions. Journal of Learning Disabilities 31(4): 374-385.

Campbell, Cary 2017. Learning that reflects the living: Aligning anticipation and edusemiotics. Public Journal of Semiotics 8(1): 1-25.

- 2018. Returning 'learning' to education: Toward an ecological conception of learning and teaching. Sign Systems Studies 46(4): 538-568.

- 2019. Educating semiosis: Foundational concepts for an ecological edusemiotic. Studies in Philosophy and Education 38(3): 291-317.

Caporael, Linnda R.; Griesemer, James R.; Wimsatt, William C. (eds.) 2014. Developing Scaffolds in Evolution, Culture, and Cognition. (The Vienna Series in Theoretical Biology.) Cambridge: The MIT Press.

Cazden, Courtney B. 1979. Peekaboo as an Instructional Model: Discourse Development at Home and at School. Palo Alto: Stanford University Department of Linguistics.

31 Acknowledgements. Alin Olteanu receives research funding from the Estonian Research Council (grant MOBJD346). Cary Campbell travelled to Estonia to conduct research at the University of Tartu thanks to the generous support of a DORA Plus grant for visiting doctoral researchers and a Doctoral Fellowship from the Social Sciences and Humanities Research Council (Canada). The work is related to PRG314. 
Chemero, Anthony 2006. Information and direct perception: A new approach. In: Farias, Priscila; Queiroz, João (eds.), Advanced Issues in Cognitive Science and Semiotics. Aachen: Shaker Press, 55-72.

Clark, Andy 2008. Supersizing the Mind: Embodiment, Action, and Cognitive Extension. New York: Oxford University Press.

Cobley, Paul (ed.) 2010. The Routledge Companion to Semiotics. London: Routledge.

- 2016. Cultural Implications of Biosemiotics. (Biosemiotics 15.) Dordrecht: Springer.

Colapietro, Vincent M. 1993. Glossary of Semiotics. New York: Paragon House.

Costall, Alan 2012. Canonical affordances in context. Avant 3(2): 85-93.

CP = Peirce, Charles S. 1931-1958. Collected Papers of Charles Sanders Peirce. (Vols. 1-6, Hartshorne, Charles; Weiss, Paul, eds., 1931-1935; vols. 7-8, Burks, Arthur W., ed., 1958.) Cambridge: Harvard University Press. [In-text references are to CP, followed by volume and paragraph numbers.]

Culler, Jonathan 1980. Literary competence. In: Tompkins, Jane P. (ed.), Reader-Response Criticism: From Formalism to Post-Structuralism. Baltimore: Johns Hopkins University Press, 101-117.

Cunningham, Donald J. 1988. Abduction and affordance: A semiotic view of cognition. (Paper presented at the Annual Meeting of the American Educational Research Association (New Orleans, LA, April 5-9, 1988). Manuscript, ERIC number ED297033.)

- 1998. Cognition as semiosis: The role of inference. Theory \& Psychology 8(6): 827-840.

D’Aquili, Eugene G.; Laughlin, Charles D.; McManus, John 1979. The Spectrum of Ritual: A Biogenetic Structural Analysis. New York: Columbia University Press.

Donahue, Mavis L.; Lopez-Reyna, Norma A. 1998. Conversational maxims and scaffolded learning in children with learning disabilities: Is the flying buttress a better metaphor? Journal of Learning Disabilities 31(4): 398-403.

Dotov, Dobromir G.; Nie, Lin; Wit, Matthieu M. de 2012. Understanding affordances: History and contemporary development of Gibson's central concept. Avant 3(2): 28-39.

Eco, Umberto 1999. Kant and the Platypus: Essays on Language and Cognition. San Diego: The Harvest Book, Harcourt.

Elleström, Lars 2018. A medium-centered model of communication. Semiotica 224: 269-293.

- 2019. Modelling human communication: Mediality and semiotics. In: Olteanu, Alin; Stables, Andrew; Borțun, Dumitru (eds.), Meanings \& Co.: The Interdisciplinarity of Communication, Semiotics and Multimodality. (Numanities - Arts and Humanities in Progress 6.) Cham: Springer, 7-32.

Faraj, Samer; Azad, Bijan 2012. The materiality of technology: An affordance perspective. In: Leonardi, Paul M.; Nardi, Bonnie A.; Kallinikos, Jannis (eds.), Materiality and Organizing: Social Interaction in a Technological World. Oxford: Oxford University Press, 237-258.

Fauconnier, Gilles; Turner, Mark 2002. The Way We Think: Conceptual Blending and the Mind's Hidden Complexities. New York: Basic Books.

Favareau, Donald 2010. Introduction: An evolutionary history of biosemiotics. In: Favareau, Donald (ed.), Essential Readings in Biosemiotics: Anthology and Commentary. (Biosemiotics 3.) Dordrecht: Springer, 1-77.

Favareau, Donald; Gare, Arran 2017. The biosemiotic glossary project: Intentionality. Biosemiotics 10(3): 413-459. 
Favareau, Donald; Kull, Kalevi 2015. On biosemiotics and its possible relevance to linguistics. In: Velmezova, Ekaterina; Kull, Kalevi; Cowley, Stephen (eds.), Biosemiotic Perspectives on Language and Linguistics. (Biosemiotics 13.) Cham: Springer, 13-28.

Fei, Victor Lim 2004. Problematising 'semiotic resource'. In: Ventola, Eija; Charles, Cassily; Kaltenbacher, Martin (eds.), Perspectives on Multimodality. (Document Design Companion Series 6.) Amsterdam: John Benjamins Publishing Company, 51-62.

Feil, Sebastian; Olteanu, Alin 2018. Abduction, hermeneutics and the interpretation of interpretations. Human Arenas 1(2): 206-222.

Fernández, Eliseo 2015a. Evolution of signs, organisms and artifacts as phases of concrete generalization. Biosemiotics 8(1): 91-102.

- 2015b. Signs, dispositions, and semiotic scaffolding. Progress in Biophysics and Molecular Biology 119(3): 602-606.

Festinger, Leon 1957. A Theory of Cognitive Dissonance. California: Stanford University Press.

Fodor, Jerry A.; Pylyshyn, Zenon 1981. How direct is visual perception? Some reflections on Gibson's 'ecological approach'. Cognition 9(2): 139-196.

Gibson, James J. 1950. The Perception of the Visual World, Cambridge: Riverside Press.

- 1966. The Senses Considered as Perceptual Systems. Boston: Houhhton-Mifflin.

- 1979. The Ecological Approach to Visual Perception. Boston: Houghton Mifflin.

Ginsburg, Gerald P. 1990. The ecological perception debate: An affordance of the Journal for the Theory of Social Behaviour. Journal for the Theory of Social Behaviour 20(4): 347-364.

Gordon, Ian E. 2004. Theories of Visual Perception. New York: Psychology Press.

Heft, Harry 1989. Affordances and the body: An intentional analysis of Gibson's ecological approach to visual perception. Journal for the Theory of Social Behaviour 19(1): 1-30.

- 1990. Perceiving affordances in context: A reply to Chow. Journal for the Theory of Social Behaviour 20(3): 277-284.

- 2001. Ecological Psychology in Context. Mahwah: Lawrence Erlbaum Associates.

Heschl, Adolf 1990. L = C: A simple equation with astonishing consequences. Journal of Theoretical Biology 145: 13-40.

Hoffmeyer, Jesper 2007. Semiotic scaffolding of living systems. In: Barbieri, Marcello (ed.), Introduction to Biosemiotics: The New Biological Synthesis. Dordrecht: Springer, 149-166.

- 2008. Biosemiotics: An Examination into the Signs of Life and the Life of Signs. Scranton: University of Scranton Press.

- 2014a. The semiome: From genetic to semiotic scaffolding. Semiotica 198: 11-31.

- 2014b. Semiotic scaffolding: A biosemiotic link between sema and soma. In: Cabell, Kenneth R.; Valsiner, Jaan (eds.), The Catalyzing Mind: Beyond Models of Causality. (Annals of Theoretical Psychology 11.) New York: Springer, 95-110.

- 2015. Introduction: Semiotic scaffolding. Biosemiotics 8(2): 153-158.

- 2018. Knowledge is never just there. Biosemiotics 11(1): 1-5.

Ingold, Tim 2000. The Perception of the Environment: Essays on Livelihood, Dwelling and Skill. Abingdon: Routledge.

- 2009. Point, line and counterpoint: From environment to fluid space. In: Berthoz, Alain; Christen, Yves (eds.), Neurobiology of "Umwelt": How Living Beings Perceive the World. (Research and Perspectives in Neurosciences.) Berlin: Springer.

- 2011. Being Alive: Essays on Movement, Knowledge and Description. Abingdon: Routledge. 
- 2019. Confession of a semiophobe. In: Cometti, Geremia; Le Roux, Pierre; Manicone, Tiziana; Martin, Nastassja (ed.), Au seuil de la forêt: Hommage à Philippe Descola l'anthropologue de la nature. Paris: Tautem, 471-484.

Jewitt, Carey 2008. Multimodality and literacy in school classrooms. Review of Research in Education 32(1): 241-267.

Kauffman, Stuart A. 2000. Investigations. New York: Oxford University Press.

Konderak, Piotr 2018. Mind, Cognition, Semiosis: Ways to Cognitive Semiotics. Lublin: Maria Curie-Sklodowska University Press.

Kress, Gunther 2003. Literacy in the New Media Age. London: Routledge.

- 2010. Multimodality: A Social Semiotic Approach to Contemporary Communication. London: Routledge.

Kress, Gunther; Leeuwen, Theo van 2001. Multimodal Discourse: The Modes and Media of Contemporary Communication. London: Arnold.

Kull, Kalevi 2012. Scaffolding. In: Favareau, Donald; Cobley, Paul; Kull, Kalevi (eds.), A More Developed Sign: Interpreting the Work of Jesper Hoffmeyer. (Tartu Semiotics Library 10.) Tartu: Tartu University Press, 227-230.

- 2014. Catalysis and scaffolding in semiosis. In: Cabell, Kenneth R.; Valsiner, Jaan (eds.), The Catalyzing Mind: Beyond Models of Causality. (Annals of Theoretical Psychology 11.) New York: Springer, 111-121.

- 2015. Evolution, choice, and scaffolding: Semiosis is changing its own building. Biosemiotics 8(2): 223-234.

- 2018. Choosing and learning: Semiosis means choice. Sign Systems Studies 46(4): 452-466.

- 2020. Semiotic fitting and the nativeness of community. Biosemiotics 13(1).

Lakoff, George; Johnson, Mark 1999. Philosophy in the Flesh: The Embodied Mind and its Challenges to Western Tóhought. Chicago: Chicago University Press.

López Cano, Rubén 2006. What kind of affordances are musical affordances? A semiotic approach. Paper presented at Lascolto musicale: condotte, pratiche, grammatiche, terzo simposio internazionale sulle scienze del linguaggio musicale, Bologna (23-25 February 2006).

Majchrzak, Ann; Faraj, Samer; Kane, Gerald C.; Azad, Bijan 2013. The contradictory influence of social media affordances on online communal knowledge sharing. Journal of ComputerMediated Communication 19(1): 38-55.

Martin, Bronwen; Ringham, Felizitas 2006. Key Terms in Semiotics. London: Continuum.

McGrenere, Joanna; Ho, Wayne 2000. Affordances: Clarifying and evolving a concept. In: Fels, Sidney S.; Poulin, Pierre (eds.), Proceedings Graphics Interface 2000. Montréal: Canadian Information Processing Society, 179-186.

Menin, Damiano; Schiavio, Andrea 2012. Rethinking musical affordances. Avant 3(2): 201-215.

Merleau-Ponty, Maurice 1995. La nature: notes, cours de Collège de France. Paris: Seuil.

Michaels, Claire F.; Carello, Claudia 1981. Direct Perception. New Jersey: Prentice Hall.

Mittelberg, Irene 2019. Peirce's universal categories: On their potential for gesture theory and multimodal analysis. Semiotica 228: 193-222.

Morgan, Augustus de 1840. First Notions of Logic (Preparatory for the Study of Geometry). (2nd ed.) London: Taylor and Walton.

Moriarty, Sandra E. 2002. The symbiotics of semiotics and visual communication. Journal of Visual Literacy 22(1): 19-28. 
Nadin, Mihai 2017. Anticipation and the brain. In: Nadin, Mihai (ed.), Anticipation and Medicine. New York: Springer, 147-175.

Niveleau, Charles-Édouard 2006. Le concept gibsonien d'affordance: entre filiation, rupture er reconstruction conceptuelle. Intellectica 43(1): 159-199.

Noble, William G. 1981. Gibsonian theory and the pragmatist perspective. Journal for the Theory of Social Behaviour 11(1): 65-85.

- 1991. Ecological realism and the fallacy of "objectification”. In: Still, Arthur; Costall, Alan (eds.), Against Cognitivism: Alternative Foundations for a Cognitive Psychology. London: Harvester Wheatsheaf.

Norman, Donald A. 1988. The Psychology of Everyday Things. New York: Basic Books.

Nöth, Winfried 1998. Ecosemiotics. Sign Systems Studies 26: 332-343.

- 2010. The semiotics of teaching and the teaching of semiotics. In: Semetsky, Inna (ed.), Semiotics Education Experience. (Educational Futures: Rethinking Theory and Practice 43.) Rotterdam: Sense Publishers, 1-19.

Olteanu, Alin 2019. Multiculturalism as Multimodal Communication: A Semiotic Perspective. (Numanities - Arts and Humanities in Progress 9.) Cham: Springer.

Olteanu, Alin; Campbell, Cary 2018. A short introduction to edusemiotics. Chinese Semiotic Studies 14(2): 245-260.

Olteanu, Alin; Stables, Andrew 2018. Learning and adaptation: Semiotic perspectives. Sign Systems Studies 46(4): 409-434.

Pea, Roy D. 2004. The social and technological dimensions of scaffolding and related theoretical concepts for learning, education, and human activity. The Journal of the Learning Sciences 13(3): 423-451.

Pearson, Charls 2018. In memoriam: Eliseo Fernández. Chinese Semiotic Studies 14(4): 393418.

Percy, Walker 1957. Semiotic and a theory of knowledge. The Modern Schoolman 34(4): 225246.

Pikkarainen, Eetu 2018. Adaptation, learning, Bildung: Discussion with edu- and biosemiotics. Sign Systems Studies 46(4): 435-451.

Pol, Janneke van de; Volman, Monique; Beishuizen, Jos 2010. Scaffolding in teacher-student interaction: A decade of research. Educational Psychology Review 22(3): 271-296.

Puntambekar, Sadhana; Hübscher, Roland 2005. Tools for scaffolding students in a complex learning environment: What have we gained and what have we missed? Educational Psychologist 40(1): 1-12.

Reybrouck, Mark 2012. Musical sense-making and the concept of affordance: An ecosemiotic and experiential approach. Biosemiotics 5(3): 391-409.

- 2015. Music as environment: An ecological and biosemiotic approach. Behavioral Sciences 5(1): 1-26.

Rodríguez Higuera, Claudio Julio; Bennett, Tyler James (eds.) 2016. Concepts for Semiotics. (Tartu Semiotics Library 16.) Tartu: University of Tartu Press.

Rodríguez Higuera, Claudio Julio; Kull, Kalevi 2017. The biosemiotic glossary project: The semiotic threshold. Biosemiotics 10(1): 109-126.

Ruitenberg, Claudia W. 2019. Plus ça change: The persistence of 'skill talk' in competency discourse. Philosophical Inquiry in Education 26(2): 124-136.

Sanders, John T. 1997. An ontology of affordances. Ecological Psychology 9(1): 97-112. 
Scaratino, Andrea M. 2003. Affordances explained. Philosophy of Science 70(5): 949-961.

Schyff, Dylan van der; Schiavio, Andrea 2017. Evolutionary musicology meets embodied cognition: Biocultural coevolution and the enactive origins of human musicality. Frontiers in Neuroscience 11(519): 1-18.

Scruggs, Thomas E.; Mastropieri, Margo A. 1998. What happens during instruction: Is any metaphor necessary? Journal of Learning Disabilities 31(4): 404-408.

Sebeok Thomas A. 1991. A Sign Is Just a Sign. (Advances in Semiotics.) Bloomington: Indiana University Press.

- 2001[1994]. Signs: An Introduction to Semiotics. Toronto: University of Toronto Press.

Sebeok, Thomas A.; Danesi, Marcel 2000. The Forms of Meaning: Modeling Systems Theory and Semiotic Analysis. (Approaches to Applied Semiotics 1.) Berlin: Mouton de Gruyter.

- 2010. Encyclopedic Dictionary of Semiotics. (3 vols. 3rd ed.) Berlin: Mouton de Gruyter.

Shank, Jeffrey C.; May, Christopher J.; Joshi, Sanjay S. 2014. Models as scaffolds for understanding. In: Caporael, Linnda R.; Griesemer, James R.; Wimsatt, William C. (eds.), Developing Scaffolds in Evolution, Culture, and Cognition. (The Vienna Series in Theoretical Biology.) Cambridge: The MIT Press, 147-167.

Shvarts, Anna; Bakker, Arthur 2019. The early history of the scaffolding metaphor: Bernstein, Luria, Vygotsky, and before. Mind, Culture and Activity 26(1): 4-23.

Shotter, John D. 1983. "Duality of structure" and "intentionality" in an ecological psychology. Journal for the Theory of Social Behaviour 13(1): 19-43.

Stables, Andrew 2005. Living and Learning as Semiotic Engagement: A New Theory of Education. Lewiston: Edwin Mellen Press.

- 2006. Sign(al)s: Living and learning as semiotic engagement. Journal of Curriculum Studies 38(4): 373-387.

- 2012. Be(com)ing Human: Semiosis and the Myth of Reason. Rotterdam: Sense Publishers.

- 2019. New Localism: Living in the Here-and-Now. Cham: Springer.

Stables, Andrew; Nöth, Winfried; Olteanu, Alin; Pesce, Sébastien; Pikkarainen, Eetu 2018. Semiotic Theory of Learning: New Perspectives in the Philosophy of Education. London: Routledge.

Stjernfelt, Frederik 2006. The semiotic body: A semiotic concept of embodiment? In: Nöth, Winfried (ed.), Semiotic Bodies, Aesthetic Embodiments, and Cyberbodies. Kassel: Kassel University Press, 13-48.

- 2014. Natural Propositions: The Actuality of Peirce's Doctrine of Dicisigns. Boston: Docent Press.

Stoffregen, Thomas A. 2000. Affordances and events. Ecological Psychology 12(1): 1-28.

Stone, C. Addison 1993. What is missing in the metaphor of scaffolding? In: Forman, Ellice A.; Minick, Norris; Stone, C. Addison (eds.), Contexts for Learning: Sociocultural Dynamics in Children's Development. New York: Oxford University Press, 169-183.

- 1998a. The metaphor of scaffolding: Its utility for the field of learning disabilities. Journal of Learning Disabilities 31(4): 344-364.

- 1998 b. Should we salvage the scaffolding metaphor? Journal of Learning Disabilities 31(4): 409-413.

Todorov, Tzvetan 1978. The birth of occidental semiotics. In: Bailey, Richard W.; Matejka, Ladislav; Steiner, Peter (eds.), The Sign: Semiotics around the World. (Michigan Slavic Publications 9.) Ann Arbor: University of Michigan Press, 1-42. 
Tomlinson, Gary 2015. A Million Years of Music: The Emergence of Human Modernity. New York: Zone Books.

Tønnessen, Morten 2015. The biosemiotic glossary project: Agent, agency. Biosemiotics 8(1): 125-143.

Tønnessen, Morten; Magnus, Riin; Brentari, Carlo 2016. The biosemiotic glossary project: Umwelt. Biosemiotics 9(1): 129-149.

Treem, Jeffrey W., Leonardi, Paul M. 2013. Social media use in organizations: Exploring affordances of visibility, editability, persistence, and association. Annals of The International Communication Association 36(1): 143-189.

Uexküll, Jakob von 1982[1940]. The theory of meaning. (Stone, Barry; Weiner, Herbert, trans.) Semiotica 42(1): 25-82.

Veer, René van der; Valsiner, Jaan 1991. Understanding Vygotsky: A Quest for Synthesis. Cambridge: Blackwell.

Vygotsky, Lev S. 1978. Mind in Society: The Development of Higher Psychological Processes. Cambridge: Harvard University Press.

- 1986[1934]. Thought and Language. Cambridge: MIT Press.

Vygotsky, Lev S.; Luria, Alexander R. 1930. Etyudy po istorii povedeniya. Obez'yana. Primitiv. Rebenok. Moscow, Leningrad: Gosudarstvennoe Izdatel'stvo. [Выготский, Л. С.; Лурия, А. Р. 1930. Этюдь по истории поведения: обезьяна, примитив, ребенок. Москва, Ленинград: Государственное Издательство.]

Wimsatt, William C. 2014. Entrenchment and scaffolding: An architecture for a theory of cultural change. In: Caporael, Linnda R.; Griesemer, James R.; Wimsatt, William C. (eds.), Developing Scaffolds in Evolution, Culture, and Cognition. (The Vienna Series in Theoretical Biology.) Cambridge: The MIT Press, 77-105.

Wimsatt, William C.; Griesemer, James R. 2007. Reproducing entrenchments to scaffold culture: The central role of development in cultural evolution. In: Sansom, Roger; Brandon, Robert N. (eds.), Integrating Evolution and Development: From Theory to Practice. Cambridge: MIT Press, 227-324.

Windsor, W. Luke 2004. An ecological approach to semiotics. Journal for the Theory of Social Behaviour 34(2): 179-198.

Windsor, W. Luke; Bézenac, Christophe de 2012. Music and affordances. Musicae Scientiae 16(1): 102-120.

Wood, David; Bruner, Jerome S.; Ross, Gail 1976. The role of tutoring in problem solving. Journal of Child Psychology and Psychiatry and Allied Disciplines 17(2): 89-100.

Zlatev, Jordan 2003. Meaning = Life (+ Culture). An outline of a unified biocultural theory of meaning. Evolution of Communication 4(2): 253-296.

Zlatev, Jordan; Sonesson; Göran; Konderak, Piotr (eds.) 2016. Meaning, Mind and Communication: Explorations in Cognitive Semiotics. (New edition.) Frankfurt am Main: Peter Lang. 


\section{Обучение и знание как семиозис: расширение концептуального аппарата семиотики}

Если все знания рождаются в процессе семиозиса, то в семиотический инструментарий следует добавить дополнительные понятия. Вместе с тем, семиотические понятия должны быть определены через другие семиотические понятия. Мы рассматриваем возможность определения понятий когнитивных процессов и явлений с помощью семиотических терминов. В частности, мы концентрируемся на понятиях, имеющих отношение к теории познания, таких как обучение, знание, доступность (affordance), подпорка (scaffolding), ресурсы, компетенция, память и некоторые другие. Даем их предварительные определения с семиотической точки зрения, что позволяет также показать их взаимосвязанность. Переосмысление этих терминов помогает избежать как физикализма, так и психологизма, демонстрируя эпистемологические характеристики взаимоотношения организмов и среды через семиотическое понимание приспособленности. Также мы вкратце обсудим значение наших введенных заново определений в качестве вклада в семиотическую теорию познания, которая имеет отношение как к гуманитарным наукам, так и к наукам о жизни, не забывая при этом об их значимости для образования и психологии, а также для социальных семиотических исследований и исследований в области мультимодальности.

\section{Õppimine ja teadmine kui semioos: semiootika mõistestiku laiendamine}

Kui kogu teadmine pärineb semioosist, siis tuleb semiootika seniste vahendite hulka lisada rohkem mõisteid. Semiootika mõisteteks on need, mis on defineeritud teiste semiootikamõistete kaudu. Näeme võimalust laiendada semiootika mõistestikku sel teel, et defineerida tajuprotsessi mõisted ja nähtused semiootiliste mõistete kaudu. Võtame selleks käsile teadmisteooriaga seotud mõisted nagu õppimine, teadmine, võimaldus (affordance), toestus (scaffolding), vahendid, pädevus, mälu ja mõned teised. Esitame nende mõistete definitsioonide esialgsed semiootikakaudsed sõnastused, sellega ühtaegu neid ka omavahel seostades. Nende mõistete niisugune ümberdefineerimine aitab vältida nii füsikalismi kui psühhologismi, tuues esile organismide keskkonnasuhete epistemoloogilise tahu semiootilise sobitumise tähenduses. Arutledes iga mõiste ümberdefineerimise juures nende osa üle semiootilises teadmisteoorias (millel on roll nii humanitaarteaduste kui eluteaduste jaoks), toome esile ka rakendatavuse haridusteaduses ja psühholoogias, samuti sotsiosemiootikas ja multimodaalsuse uuringutes. 